\title{
Toplulukçu Kültürün Öz Liderlik Algısı Üzerine Etkisi: Hizmet Sektöründe Bir Araştırma
}

\author{
DOI: $10.26466 /$ opus.585045
}

*

\section{Ayșen Akbaș Tuna*}

* Öğ. Gör. Dr. Ankara Hacı Bayram Veli Üni., Bankacılık ve Sigortacılık Y.O, Ankara / Türkiye E-Posta: aysenakbastuna@hotmail.com ORCID:0000-0003-4615-4374

Öz

Günümüz iş dünyasında, hızlı ve sürekli olan değiş̧im ve gelişmeler yaşanmaktadır. Bu nedenle işletmeler, sahip oldukları insan kaynakların en iyi şekilde yönlendirmek ve merkezi bir yönetimden daha esnek bir yönetime geçmek gereği duymaktadır. Böyle bir ortamda işletmelerde liderlik tarzları da bu değişime uyum sağlayacak şekilde değişmekte ve çeşitlenmektedir. Bazı davranışsal ve bilişsel stratejilerin kullanımı yoluyla bireylerin kendi davranışlarını kontrol ettikleri bir süreç olarak adlandırılan öz liderlik kavramı, çeşitli kültürel değerlere sahip toplumlarda çeşitli düzeylerde görülen bir lidelik çeşidi olarak karşımız çıkmıştır. Bu çalı̧̧mada da, toplumsal kültürel boyutlardan toplulukçuluk boyutunun, davranış odakl öz liderlik stratejileri üzerine olan etkisi araştırılmaktır. Bu kapsamda, toplumsal kültürel değerlerin toplulukçuluk alt boyutu ile davranış odaklı öz liderliğin alt boyutları arasındaki ilişkiler ortaya konmaya çalışılmışıır. Çalışmanın örneklemini Ankara'daki hizmet sektöründe çalışan 374 birey oluşturmaktadır. Oluşturulan modelin doğrulanması ve beklenen etkinin test edilmesi için AMOS 22; tanımlayıct istatistikler için ise SPSS 20 paket programlarından yararlanılmıştır. Çalışmada toplulukçuluğun; davranış odaklı öz liderlik stratejilerinden kendini ödüllendirme, kendini gözlemleme ve kendine hatırlatıclar belirleme stratejilerini anlamlı ve pozitif yönde; kendini cezalandırma stratejisini ise, anlamlı ve negatif yönde etkilediği sonucuna ulaşılmışıır.

Anahtar Kelimeler: Öz liderlik, Kültürel Boyutlar, Toplulukçuluk 


\title{
The Impact of Collectivistic Culture on Self Leadership: A Study in Service Sector
}

\begin{abstract}
In today's business world, rapid and continuous changes and developments are taking place. For this reason, businesses need to optimize their human resources and move from centralized management to a more flexible management. In such an environment, leadership styles in enterprises change and diversify to adapt to this change. The concept of self-leadership, which is called as a process in which individuals control their own behavior through the use of some behavioral and cognitive strategies, has emerged as a kind of leadership that is seen at various levels in societies with various cultural values. This study was conducted to explore the effect of collectivism on behavior-focused self-leadership strategies. In this context, it has been tried to reveal the relations between collectivism sub-dimension of social cultural values and behavior-oriented self-leadership. The sample of the study consists of 374 individuals working in the service sector in Ankara. In order to verify the created model and to test the expected effect, Amos 22 and for the descriptive statistics SPSS 20 package programs were used. In the study; it was concluded that collectivism has significant and positive effects on behavior-oriented self-leadership strategies named self-rewarding, self-observation and self-reminder. Also collectivism has a significant negative impact on the strategy of self-punishment.
\end{abstract}

Keywords: Selfleadership, Cultural Dimensions, Collectivism 


\section{Giriş}

İş dünyasındaki hızlı değişim nedeniyle, yönetilmesi gereken en önemli unsur olan insanı, zamanında ve doğru bir şekilde yönetememe riskini en aza indirmek için, yönetimler tarafından bir takım yöntemler geliştirilip bunlardan yararlanılmasının gerekli olduğu söylenebilir. Çalışanların dişsal motivasyondan çok kendi kendilerine harekete geçmelerini sağlayacak içsel motivasyonlarını arttırmak ve sorumluluk bilinci ile hareket etmelerini sağlamak bu anlamda yönetimlerin işlerini kolaylaştıracaktır.

Son yıllarda çok uluslu kuruluşlar, iş ortamındaki hızlı değişikliklere cevaben yeniden yapılandırılmış ve merkezi olmayan, organik tip organizasyon yapılarına yönelmiştir. Kendini yönlendirme ve kendine etki etme konusunda yüksek düzeyde kapasite ve beceriye sahip kişiler, organizasyon yapılarının ve ortamlarının dinamik değişimlerine daha başarılı ve etkili bir şekilde yanıt verebilirler. Bu nedenle öz liderlik kavramı, "insanların kendilerini yönlendirme ve kendi motivasyonlarını sağlama yoluyla gerçekleştirmeleri gereken öz etki (kendilerini etkileme) süreci olarak tanımlanmakta ve yönetim araştırmalarında önemli bir kavram haline gelmektedir (Ho ve Nespit, 2013, s.241). Yöneticiler de eğitim programları yoluyla işyerinde öz liderlik beceri ve davranışlarını arttırmaya yönelik tasarlanan öz liderlik kavramını benimsemişlerdir (Neck ve Houghton, 2006, s.271).

Dünyada çok uluslu kuruluşların artması nedeniyle farklı kültürel değerlere sahip işgörenlerin bir arada çalışması söz konusu olmuştur. Yukarıda da değinildiği gibi, çok uluslu işletmelerin organizasyon yapılarına uyum sağlayabilecek işgörenlerde öz liderlik becerilerinin gelişmiş olması önem taşımaktadır. Bu durumun iş ortamını nasıl etkileyeceği ise araştırılması gereken bir konu olarak gündeme gelmiştir. Bu nedenle öz liderlik kavramının kültürler arası uygulanabilirliğine yönelik çalışmalar yapılmıştır. Georgianna (2007, s.573), kültür ve özliderlik ile ilgili yapılan çalışmalarda ortaya çıan soruyu, bireyciliği vurgulayan bireyci kültürler ile grup üyeliğinin önemini vurgulayan toplulukçu kültürler arasında her bir kültürde bulunan öz liderlik stratejileri nedeniyle performans farklılıklarının olup olmadığı şeklinde tanımlamıştır. Houghton ve Neck (2002) tarafından geliştirilen gözden geçirilmiş öz liderlik ölçeği ise pek 
çok yazar tarafından (Alves, vd. 2006; Georgianna, 2007; Ho ve Nespit, 2013; Houghton, vd., 2012; Houghton, vd., 2014; Neubert ve Wu, 2006) bu ölçeğin kültürler arası uygulanabilirliğini test etmek için çeşitli çalışmalarda kullanılmıştır. Türkiye'de Doğan ve Şahin (2008) bu uyarlama çalışmasını kamu sektöründe çalışanlar üzerinde gerçekleştirirken; Tabak, vd. (2013) ise uyarlama çalışmasını yönetici ve çalışanlar üzerinde yapmıştır. Bu çalışmada da Tabak vd. (2013) tarafından yapılan çalışma sonucunda, orjinal ölçekten farklı oluşan davranış odaklı öz liderlik stratejileri boyutu kullanılmıştır.

Kültür ise bir grup ya da zümrenin üyelerini diğer insanlardan ayıran zihnin toplu programlanmasıdır (Hofstede, 2011, s.3). Öz-liderlik kavramı ise Amerika kökenli bir modeldir ve Hofstede tarafından tanımlanan Amerikan kültür değerlerine dayanmaktadır.

Öz liderlik konusu ile ilgili Avrupa, Kuzey Amerika ve Avustralya' da yapılan çalışmaların evrensel bir geçerliliği olmadığını savunan Georgianna (2007), araştırma bulgularının sadece bu bölgelerde genellenebileceğini belirtmiştir. Bu nedenle yapılan çalışmaların batı kültürü olarak adlandırılan bu kültürlerin dışındaki kültürler için bir faydası bulunmamaktadır. Batı kültürü dışında kalan diğer kültürler ise küreselleşme sürecinde hızlı bir şekilde değişim göstermektedir. Batı kültürler, batılı olmayan kültürleri ağırlıklı olarak ticaret, göç ve bilgi teknolojilerinin yayılması yoluyla etkilediği için bu kültürler, küreselleşme sürecinde belirgin değişiklikler geçirmektedir. Bu kültürlere doğru genişleyen batılı şirketler, iletişim tarzları, bilgi gücü kullanımı, öğrenme ve hedef belirleme açısından önemli kültürel zorluklarla karşılaşmaktadır ve batılı olmayan çalışanların batılı yöneticiler tarafından yönetilmesi farklı zorluklar getirmektedir. Bu nedenle kültür ve öz liderlik ile ilgili çalışmaların, batılı olmayan kültürlerde de uygulanması için şartlar olgunlaşmıştır.

$\mathrm{Bu}$ çalışmada da toplumsal kültür boyutlarından toplulukçuluk boyutunun, öz liderlik stratejilerinden davranış odaklı öz liderlik stratejileri üzerinde etkisi olup olmadığı araştırılmıştır. Yapılan yerli alanyazın taramasında toplumsal kültürel değerler ve öz liderlik arasındaki ilişkiyi araştırmaya yönelik herhangi bir çalışmaya rastlanmamıştır. Bu nedenle araştırmanın yerli alanyazına katkıda bulunacağı düşünülmektedir. 


\section{Öz Liderlik Kavramı}

Öz liderlik, bazı davranışsal ve bilişsel stratejilerin kullanımı yoluyla bireylerin kendi davranışlarını kontrol ettikleri, kendilerini etkileyen ve yönlendiren bir süreçtir. Öz liderlik kavramı ilk olarak 1980'lerin ortalarında, klinik öz kontrol teorisine dayanan ve "liderliğe ikame yaklaşımlar" kavramından esinlenen, kendi kendini yönetme durumunun genişlemesi olarak ortaya çıkmıştır (Neck ve Houghton, 2006, s.270). Manz (1986, s.585) öz-liderlik kavramını açıklarken bu kavramın, alanyazındaki sosyal öğrenme teorisi ve öz kontrol ile ilgili çalışmalardan ortaya çıktığına, organizasyon alanyazınında ise bu sürecin genellikle öz yönetim olarak anıldığına değinmiştir. Houghton ve Neck $(2002$, s.672) ise öz liderliğin, genellikle öz-düzenleme, öz-kontrol ve öz-yönetimin, davranış odaklı stratejilerini içeren ve ayrıca içsel motivasyon kuramlarından, sosyal bilişsel kuram ve pozitif bilişsel kuramdan türetilen bilişsel odaklı strateji kümelerini belirten öz etkinin (kendini etkileme) geniş bir konsepti olarak tasvir edildiğini belirtmiştir.

Burada, öz liderlik, kişileri doğal bir görev motivasyonu göstermeye yönlendirdiği gibi doğal motivasyon olmadan zorunlu işleri yapmaları için kendilerini yönetme ile ilgili kapsamlı bir öz etki perspektifi olarak kavramsallaştırılmıştır (Manz, 1986, s.589). Öz yönetim tekniklerinin uygulanması ise çalışanlara sistem tarafından tanımlanan bir standardın yerine getirilmesi için bir görevin nasıl tamamlanacağına dair önemli bir öz etki yaratma eğiliminde iken; öz liderlik, görevin nasıl yapılması gerektiğinin yanı sıra ne yapılması gerektiğini ve neden yapılması gerektiğini ele alır (Georgianna, 2007, s.570).

Pearce ve Manz (2005)'a göre; öz liderlik kendi kendine yöneticiliğin ötesinde, yönetimde her zaman "ne-neden-nasıl" sorularına yanıt arayan ve tüm çalışanların bir bilgi işçisi olarak görülmesi gerektiğini de ön plana çıkaran bir yaklaşımdır. Öz liderlik, kendi kendine fayda sağlama algısıyla yakın ilişkili liderlik tarzlarından birisi olan, paylaşımcı liderliğin temelini teşkil etmektedir. Çünkü insanlar öncelikle kendilerine liderlik edebilmeli ve daha sonra da diğerleriyle bu süreci paylaşabilmelidirler (Tabak vd., 2013, s.215). Rekabet ortamında faaliyet gösteren işletmelerde geleneksel liderlikten daha çok paylaşılan liderliğe yönelik bir değişiklik gerektiği söylenebilir. 
Manz ve Sims (1991, s.23), öz liderlik konusuna "başkalarını nasıl yöneteceğimizi öğrenmeden önce, en önemli şey, kendimizi nasıl yöneteceğimizi öğrenmektir" demiş ve öz liderliği, kendi kendimizi motive etmeyi ve yönlendirmeyi başarmak için yine kendi üzerimizdeki etkimiz olarak tanımlamıştır. Yazarlar kavramı katılımcı yönetim açısından değerlendirdiklerinde, katılımcı yönetimin başarılı bir şekilde uygulanabilmesi için astların kendini yönetme becerisi kazanmış, kendi doğrularının lideri olan etkili izleyiciler olmalarının, etkili öz liderliğin özü olduğunu belirtmiştir.

Ayrıca Manz ve Sims (1991, s.22) öz liderliği, odağı büyük ölçüde takipçilerine yönelik olan süper liderliğin bir ürünü olarak görmüştür. Yani süper liderlikte liderler takipçilerin yeteneklerini açığa çıkarmaya yardım ederek birçok insanın gücüne ve bilgeliğine sahip olabilirler. Bu liderlik görüşünün odak noktası, öz liderler haline gelen takipçilerdir. Güç, liderler ve takipçiler tarafından daha eşit paylaşılmaktadır. Liderin görevi büyük ölçüde, takipçilerin organizasyona daha fazla katkıda bulunabilmeleri adına iş ve özellikle de öz liderlik için gerekli becerileri geliştirmelerine yardımcı olmaktır.

Houghton vd., (2012, s.219) çalışmalarında öz liderlik kavramının; liderlik stratejilerinin etkinliği değerlendirme, örgütsel değişim, öz liderlik ekipleri, girişimcilik, farklılık yönetimi, iş tatmini, kar amacı gütmeyen yönetim, takım performansı ve süreçleri, ardışık terfi planlama, yaratıcılık ve yenilikçilik ve etik kavramları ile uygulamalı olarak incelendiğini belirtmiştir.

Alanyazında öz liderlik stratejilerinin araştırmacılar tarafından davranış odaklı stratejiler, doğal ödül stratejileri ve yapıcı düşünce modeli stratejileri olmak üzere üç başlık altında değerlendirildiği görülmüştür (Houghton vd., 2002; Neck ve Houghton, 2006; Ho ve Nesbit, 2013).

\section{Davranış Odaklı Stratejiler}

Davranış odaklı stratejiler, davranışların yönetimini, özellikle de yapılması gerekli fakat çok da hoş olmayan görevlerle ilgili davranışların yönetimini kolaylaştırmak için bireyin öz farkındalığını arttırmaya çalışır. Bu stratejiler, kendini gözlemleme, hedef belirleme, kendini ödüllendirme, kendini cezalandırma ve kendine hatırlatıcılar belirleme boyutlarında 
incelenmektedir. Kendini gözlemleme, kişinin ne zaman ve neden belirli davranışlarda bulunduğuna dair farkındalığını arttırmayı içermektedir ve bu tür bir kişisel farkındalık, etkisiz ve verimsiz davranışların değiştirilmesi veya ortadan kaldırılması için gerekli ilk adımdır. Hedef belirleme stratejisi, hedef belirleme teorisine dayanmaktadır. Zorlu ve spesifik hedeflerin belirlenmesinin bireysel performans seviyelerini önemli ölçüde artırabileceğini göstermektedir. Kendini ödüllendirme, bireyin hedeflerine ulaşmasıyla bu başarısından dolayı takdir edilmesini, onaylanmasını, terfi ettirilmesini kısaca ödüllendirilmesini içermektedir. Hedef belirleme ile birlikte düşünüldüğünde, hedeflere ulaşmak için gereken çabanın harekete geçirilmesinde önemli ölçüde yardımcı olabilir. Kendini cezalandırma ise bireyin arzu edilmeyen davranışlarının yok edilmesine veya azaltılmasına yönelik olarak davranışlarını düzeltebilmesi için kendini olumlu yönde cezalandırmasını içermektedir. Bu anlamda, davranış odaklı öz liderlik stratejileri, başarılı çıtılara götüren pozitif istenilen davranışları teşvik ederken; başarısız çıktılara götüren negatif istenmeyen davranışları da bastırmaya yönelik olarak tasarlanmıştır (Neck ve Houghton 2006, s.270; Houghton ve Neck, 2002, s.673; Houghton, vd., 2014, s.415; Tabak vd., 2013, s.215).

\section{Doğal Ödül Stratejileri}

Doğal ödül stratejileri, bireylerin görevlerini veya aktivitelerini doğal olarak zevkli buldukları ve bu nedenle yaptıkları şeylerden zevk aldıkları için motive oldukları durumlar oluşturmak için mevcuttur (Houghton, vd., 2014, s.416).

\section{Yapıcı Düşünce Stratejileri}

Yapıcı düşünce stratejileri, olumlu ve üretken düşünce kalıplarının oluşumunu kolaylaştırmak ve performansı yapıcı bir şekilde etkileyebilecek alışılmış düşünce yolları oluşturmak için tasarlanmıştır (Houghton, vd., 2014, s.416). Bireylerin kendi zihinsel modellerini kontrol edebilmesi ve yönetebilmesi üzerine yapılandırılan bu stratejiler, başarılı performans hayal etme, kendi kendine konuşma ve düşünce/fikirleri değerlendirmedir. 


\section{Öz Liderliğe Yeni Stratejiler}

Öz-liderlik konusunda çalışan bazı teorisyenler, öz liderliğin bir takım önemli nüanslarnı yansıtan ek öz-liderlik strateji boyutları belirlemişlerdir. Örneğin bunlardan ilki olan öz-farkındalı stratejileri, bireyin uzun süreli günlük tutma ya da bir tür kayıt tutma yöntemi ile uzun süredir kendi davranışlarını sistematik olarak izlenmesine dayanmaktadır. Bugüne kadar yapılan araştırmalar, yüksek düzeyde öz farkındalığa sahip bireylerin daha güvenli, ilgi çekici ve heyecanlı olduklarını göstermektedir. Bu bireyler, daha iyi performans gösterip buna daha uzun süre devam ederler ve dış ya da bilinçsiz kontrole tabi olan bireylerden daha fazla yaratıcılık gösterirler. Bir diğer strateji ise irade stratejileridir. Hedef belirleme ve hedefe ulaşma ile ilgili stratejileri içerir. Bu stratejilerin kullanılması, istenen bir davranışı uygulayacak somut niyetler yaratarak karar alma sürecini etkiler. Bireylerin ne zaman, nerede ve nasıl hedefleri için çabalamaya başlayacaklarını ayrıntılandıran bir uygulama ile bir hedefe ulaşmaya karar vermek bir irade stratejisi örneği olabilir. Son strateji ise motivasyon stratejileridir. Motivasyon teorileri üzerine yapılan araştırmalar, ara hedefleri belirleyerek uzun vadeli hedeflerle mücadele etmeyi, hedefe ulaşmak için çabalarken kendini ödüllendirmeyi veya hoş olmayan görevleri daha büyük bir öğrenme deneyiminin bir parçası olarak görmektedir. Motivasyon stratejileri, başarılı performans sağlayan kişisel yetkinlik ve etkinliği görselleştirme süreci gibi performans sonuçlarına bilinçli olarak odaklanmayı içerir. Motivasyonel stratejilerin kullanımı, hedefe ulaşma çabası sırasında daha yüksek dayanıklılığa ve sonrasında da hedefe ulaşmada yüksek oranda etkili olmaktadır (Georgianna, 2007, s.570; Houghton, vd., 2012, s.219).

\section{Toplumsal Kültür Kavramı}

Hofstede'ye göre kültür, milletimizin, bölgemizin veya grubumuzun diğer üyeleriyle paylaştığımız ancak diğer ulusların, bölgelerin veya grupların üyeleriyle paylaşmadığımız şartlandırmalarımızın bir parçası olan kolektif bir zihinsel programlamadır. Buna göre bir kültürün değişmesi için uzun yıllar geçmesi gerekmektedir (Hofstede, 1983, s.76). Kültür, 
ebeveynlerin çocuklarına, öğretmenlerin öğrencilere, arkadaşların arkadaşlarına, liderlerin takipçilerine ve takipçilerin liderlerine aktardıkları düşünce kalıplarından oluşur (Hofstede, 1984, s.82).

Türk Dil Kurumu ise kültürü; "tarihsel, toplumsal gelişme süreci içinde yaratılan bütün maddi ve manevi değerler ile bunları yaratmada, sonraki nesillere iletmede kullanılan, insanın doğal ve toplumsal çevresine egemenliğinin ölçüsünü gösteren araçların bütünü" olarak tanımlamıştır (http://www.tdk.gov.tr).

Yine de, Hofstede kültürün, alt düzey (bireysel) ve üst düzey (toplumsal) yapılarda şekillenebileceğini kabul etmiştir. Çünkü kültür ve insanlar zaman içinde karşılıklı olarak şekillenir ve tıpkı insanların yeni kültürel alanlara (sosyal gruplar) geçebilmesi gibi, uygulama yoluyla da (kurumların yapısı ve işleyişi) kültür kavramları değişebilir (Alves, vd. 2006, s.345).

Toplumsal kültür ile ilgili pek çok çalışması olan Hofstede (1998), çalışanların tutumlarını ve örgüt kültürünü etkileyebilecek türden yönetim uygulamaları ile ilgili çalışmalarında, iletişim ve işbirliği alanındaki uygulamalar dışında, yönetsel uygulamalar ile çalışanların tutumları veya örgüt kültürü arasında bir ilişki olmadığı sonucuna varmıştır. Bu, çalışanların tutumlarını değiştirmede dil (sözlü veya sözsüz) ve sosyal etkileşimin iki önemli faktör olduğu anlamına gelmektedir. Bu bulgunun, öz yönetim teorisi ve pratiği için önemli etkileri olabilir. Öz liderlik teorisi için, dilin ve sosyal ilişkilerin önemi göz ardı edilemez, çünkü farklı kültürlerden gelen insanların yaptıkları, düşündükleri veya söyledikleri (düşünme, hissetme ve hareket etme) arasında farklılıklar ortaya çıarabilir (Alves, 2006, s.345). Buna göre öz liderliğin farklı kültürlerde farklı şekillerde ortaya çıkabileceği söylenebilir.

\section{Toplulukçuluk}

Bireycilik, bireylerin sadece kendilerine ve yakın ailelerine bakmaları gerektiğini varsaydıkları, toplum içindeki zayıf bir sosyal yapı tercihini ifade eder. Karşıtı olan toplulukçuluk ise bireylerin akrabalarının, klanlarının ya da grup içindeki diğer grupların sorgulamayan bir sadakat karşılığında kendilerine bakmalarını bekleyebilecekleri sıkı sıkıya bağlı bir sosyal yapının tercih edilmesi anlamına gelir. Bu boyut tarafından ele alınan 
temel konu, bir toplumun bireyler arasında sürdürdüğ̈̈ karşılıklı bağımlılık derecesidir (Hofstede, 1984, s.83).

Oyserman (2006) bireyselcilik ve toplulukçuluğun ardındaki kültürü incelediği çalışmasında, Hofstede' nin yapmış olduğu ve pek çok araştırmacı tarafından kabul edilen, bireyselciliğin zıttının toplulukçuluk olduğu varsayımının dişında, bireyselcilik ve toplulukçuluğun dikey bir yapı sergilediğini belirtmiştir. Bunun anlamı ise bireyselcilik ve toplulukçuluğun ve bunların psikolojik süreçler üzerindeki etkilerinin her birinin ayrı ayrı test edilmesi gerektiğidir. Çünkü her ikisi de toplumlarda bir dereceye kadar bulunmaktadır.

Triandis tarafından ise bireyselcilik vs. toplulukçuluk boyutuna ilişkin bir başka kavramsal model geliştirilmiştir. Modelde aşağıdaki dört farklı unsur bulunmaktadır (aktaran Dörtyol, 2012, s.46):

1. Yatay bireyselcilik; bağımsız öz olgusuna odaklanmakta ve her bir bireyin eşit olduğu inancını yansıtmaktadır.

2. Dikey bireyselcilik; bağımsız öz olgusuna odaklanmakta ve her bir bireyin eşit olmadığı inancını yansıtmaktadır.

3. Yatay toplulukçuluk; diğerlerine bağımlı öz olgusuna odaklanmakta ve her bir bireyin eşit olduğu inancını yansıtmaktadır.

4. Dikey toplulukçuluk; diğerlerine bağımlı öz olgusuna odaklanmakta ve her bir bireyin eşit olmadığı inancını yansıtmaktadır.

Hofstede'nin çalışmaları (1980, 1984); ülke düzeyinde yaptığı araştırma sonucunda elde edilen bireycilik skorlarının, ülkenin tüm bireyleri için geçerli olamayacağı, kullandığı deneklerin toplumun tüm katmanlarını yansıtmadığı yönüyle eleştirilmiştir. Toplumlar, homojen bir nüfus yapısına sahip olmadıklarından, ülke düzeyindeki bulguların birey düzeyinde geçerli olduğu söylenemez. Kültürel yönelimler, birey düzeyinde farklılaşırken; bu eğilimler zaman içinde de sabit kalmazlar. Kültürler, değişir ve dinamiktirler. Bu açıdan kültürler arası çalışmaların "aşırı görecelik tuzağına düşme tehlikesi vardır" ve olgudaki farklılaşmayı (ya da farklılaşmama durumunu) gerçekte neyin açıkladığının ortaya konması, "kültürün her şeyi içeren geniş yapısı" nedeniyle zor ve sorunludur. alanyazında, araştırmalara konu olan kültür boyutlarının doğrudan ölçümlenmesi gerektiği; aksi halde, değişkenlerdeki varyansın kültür kaynaklı olduğunun iddia edilemeyeceği; “birey- 
sel düzeydeki sosyal-psikolojik süreçleri anlamak için yine birey düzeyinde kültürel değerler ölçümlemesi" yapılmasının önemi vurgulanmıştır (Sakal ve Aytekin, 2014, s.52).

Markus ve Kitayama (1991) ise bireyin bağımsız ve karşılıklı bağımlı benliği bir arada barındırabileceğini vurgulamıştır. Bu boyutlar bağımsız olduğundan bir bireyin bireycilik değerlerinin yüksek olduğunu bilmemiz onun toplulukçuluğu hakkında bize bilgi vermeyebilir. Bireyler her iki boyutta veya birinde baskın varsayımlara veya değerlere sahip olabilir. "Bireycilik-toplulukçuluk eğilimleri bireylerde ya da gruplarda aynı anda ve bir arada görülebilir". Farklı durumlarda, değişik hedef gruplara karşı ya da değişik etkileşim amaçlarında bireycilik ya da toplulukçuluk ön plana çıkabilir. Bireycilik-toplulukçuluk tek bir kavram olarak değil, bireycilik ve toplulukçuluk adında iki bağımsız kavram olarak görülmelidir (Ton, 2008, s.18). Triandis (1994) ise bireysel düzeyde toplanacak verilerle yapılacak faktör analizinin, bireylerin hem bireyci hem de toplulukçu özellikleri aynı anda taşıyabileceklerini göstereceğini iddia eder. Yani, Triandis'e göre her birey, hem bireyci hem de toplulukçu eğilimlere sahiptir (aktaran: Sakal ve Aytekin, 2014, s.52,).

\section{Toplulukçuluk ve Özliderlik Arasındaki İlişki}

Her alanda olduğu gibi iş dünyasında da yaşanan hızlı ve sürekli değişimler liderlik kavramını değiştirmiş ve geliştirmiştir. Bu nedenle liderlik alanında yapılan çalışmalar sürekli olarak güncelliğini korumakta ve hem alan yazına hem de uygulamaya önemli katkılar sağlamaktadır. Küreselleşen dünyada küreselleşen kuruluşlar, farklı kültürlerden çalışanları biraraya getirdiğinden liderlik ile ilgili yeni yaklaşımların ortaya çıkması söz konusu olmuştur. Öz liderlik kavramı da farklı kültürlerden gelen çalışanların başarılı bir şekilde yönetilmesini sağlamak üzere üzerinde çalışılan bir kavram olmuştur. Alves vd. (2006)'e göre, her ne kadar bu kavram bireylerin kendi hedeflerini belirlemede özerklik derecelerine sahip olduğu varsayımını düşündürse ve ABD'den daha toplulukçu olan kültürlerde meydana gelme ihtimalini sorgulatsa da; kavram kendine önderlik yapma, kendi kendini etkileme ve kendi performansını geliştirmeyi amaçlayan bir dizi strateji olarak kabul edildiğinde çoğu toplum için uygulanabilir bir kavramdır. İlk olarak Neubert ve Wu (2006) 
Çin'de yaptıkları çalışmada toplulukçu kültürlerde öz liderlik davranışlarının sergilendiğini ortaya çıkarmışlardır. Bununla birlikte Georgianna (2007), çeşitli yollarla batı kültüründen etkilenen ve toplulukçu olarak nitelendirilen doğu kültürlerinin öz liderlik davranışı sergilemeye bu etkileşim sonucunda hazır olduğunu belirtmiştir.

$\mathrm{Bu}$ bağlamda yapılan alanyazın incelemesinde öz liderlik ile ilgili yapılan kültürler arası pek çok çalışmaya rastlanmıştır. Çalışmalar, Hofstede (1980) ve Alves vd. (2006)' in kültürel boyutlar ayrımına dayanarak, öz liderliğin diğer kültürlerde nasıl anlaşılabileceği ve uygulanabileceği sorusunu ele almıştır ve toplulukçu kültürlerdeki bireylerin, ilişkiler merkezli öz liderliği uygulama olasılığı daha yüksek olduğunu belirtmiştir.

Georgianna (2007) ise araştırmasında, kültür ve öz liderlik arasındaki ilişki nedir sorusuna cevap aramıştır ve aralıklı ölçümlerle gerçekleştirdiği çalışmasında Amerikalı öğrencilerin Çin 'li öğrenci grubuna göre daha yüksek öz liderlik özellikleri gösterdiği fakat şaşırtıcı bir şekilde Çinli öğrencilerin Amerikalı gruba göre daha yüksek bireyci özellikler gösterdiği sonucuna ulaşmıştır. Ancak çalışmasında, kültürel özelliklerin öz liderlik özerinde anlamlı bir etkisini bulamamıştır. Yapılan bu çalışma, her bir öz liderlik stratejisi yalnızca bir madde ile ölçüldüğünden öz liderlik teorisyenleri tarafından önerilen öz liderliğin teorik olarak kavramsallaştırılmasını yeterince yakalayamaması açısından eleştirilmiştir.

Houghton vd. (2014) ise çalışmasında Amerika, Çin, Almanya ve Portekiz örneklemlerini karşılaştırmıştır. Çalışmada, Çin kültürünün, Portekiz kültürünün ve hatta bireycilikte göreceli olarak yüksek olmasına rağmen, Alman kültürünün, toplulukçuluk boyutu açısından Amerika'dan farklılaştı̆̆ sonuçlarına ulaşılmıştır.

Ho ve Nesbit (2013) de diğer kültürler arası çalışmalarla benzer şekilde kültürün Hong Kong ve Avustralyalı öğrenciler arasında öz-liderlik stratejilerinin kullanımını nasıl etkilediğini incelemiştir. Çalışma davranış odaklı stratejilerin sonuçları açısından incelendiğinde Çinli öğrencilerin, kendini ödüllendirme stratejisini daha fazla kullandıkları görülürken; Avustralyalı öğrencilerin hedef belirleme ve kendine hatırlatıcılar belirleme stratejilerini daha fazla kullandıkları görülmüş̧ür. Bununla birlikte, 
kendini cezalandırma stratejisi açısından kültürel bir farklılık bulunamamiştır.

Neubert ve Wu (2006), bu çalışmada da kullanılan "Revize Edilmiş Öz Liderlik Ölçeği" nin, Çin bağlamında geçerlilik çalışmasını yapmış ve ölçeğin tamamının genellenemeyeceği sonucuna ulaşmıştır. Çalışma sonucunda en uygun öz liderlik modelinin, hedef belirleme, başarılı performans hayal etme, kendi kendine konuşma, kendini ödüllendirme ve kendini cezalandırma boyutlarını içerdiği sonucuna ulaşmıştır.

Doğan ve Şahin (2008), ölçeğin Türkçe uyarlaması, geçerlilik ve güvenilirlik çalışmasını yaptığı araştırmasında, ölçeğin bireylerin öz liderlik stratejilerini ölçmede güvenilir bir ölçme aracı olduğu fakat ölçeğin geçerliliğinin elde edilen verilerle doğrulanamadığı sonucuna ulaşmıştır.

Tabak vd. (2013) ise ölçeğin orijinal ölçekte olduğu gibi "davranış odaklı", "doğal ödül" ve "yapıcı düşünce modeli" stratejilerinden oluşan üç boyuttan meydana geldiğini ancak bu boyutların altında iki ayrı faktör olan "hedef belirleme" ve "başarılı performans hayal etme" faktörlerinin çalışmalarında tek bir faktör altında yer aldığını, bu nedenle de orijinal ölçekte dokuz olan faktör sayısının, çalışmada sekiz faktörden meydana geldiği belirtmiştir. Oluşan yeni faktör, "kendine hedef belirleyerek başarılı performans hayal etme" olarak adlandırılmıştır. Elde edilen bulgular Öz Liderlik Ölçeğinin Türkçe Formunun kabul edilebilir değerlerde güvenilir ve geçerli bir ölçek olduğunu düşündürmüştür.

Bu bağlamda çalışmanın araştırma sorusu, "Toplumların kültürlerini açıklamada kullanılan toplulukçuluk boyutunun, batı kültüründe ortaya çıkan ve kişilerin nasıl davrandıkları değil; nasıl davranmaları gerektiğini açıklayan öz yönetim teorisine dayanan, davranış odaklı öz liderlik stratejisi üzerinde bir etkisi var mıdır? şeklinde oluşturulmuştur. Araştırma sorusu oluşturulurken her bireyin, hem bireyci hem de toplulukçu eğilimlere sahip olduğu (Triandis:1994; aktaran: Sakal ve Aytekin, 2014, s.52) varsayımı da göz önünde bulundurulmuştur. 


\section{Yöntem}

\section{Araştırmanın Amacı}

Yapılan alanyazın taramasında Amerika kökenli bir model olarak ortaya çıkan Öz-liderlik kavramının Amerika gibi batı kültürleri dışında kalan kültürlerde genellenebilir, geliştirilebilir ve uygulanabilir olup olmadığının araştırıldığı görülmüştür. Araştırma sonuçlarında ise öz liderlik stratejilerinin bu kültürlerde de farklı şekillerde uygulanabildiği ortaya çıkmıştır (Alves, vd. 2006; Georgianna, 2007; Ho ve Nespit, 2013; Houghton, vd., 2012; Houghton, vd., 2014; Neubert ve Wu, 2006, Tabak, vd. 2013). Bu araştırmada da toplumsal kültürel değerlerin toplulukçuluk alt boyutunun, davranış odaklı öz liderlik stratejilerinin alt boyutları üzerinde bir etkisi olup olmadığının ortaya konması amaçlanmıştır.

\section{Araştırmanın Yöntemi}

Araştırma nicel araştırma desenlerinden nedensel ilişki tasarımı kullanılarak yapılmıştır. Veriler, anket aracılı̆̆ıyla toplanmıştır. Araştırmada kullanılan ölçeklerin geçerliliğini sağlamak için bütüncül bir yapıda doğrulayıcı faktör analizi yapılmıştır. Katılımcılara ilişkin demografik bulgular ve değişkenler arasındaki ilişkileri saptamak yönelik yapılan korelasyon analizi için SPSS paket programı kullanılmıştır. Araştırma hipotezlerini test etmek için ise yapısal eşitlik modellemesi kullanılmış ve AMOS paket programından yararlanılmıştır.

\section{Araştırmanın Modeli ve Hipotezler}

Araştırma modeli, toplumsal kültürel değerlerden biri olan toplulukçuluk boyutunun davranış odaklı öz liderlik stratejileri olan kendini ödüllendirme, kendiniz cezalandırma, kendini gözlemleme ve kendine hatırlatıcılar belirleme boyutları üzerinde etkisi olup olmadığını araştırmak üzere kurulmuş ve Şekil 1 'de gösterilmiştir. 


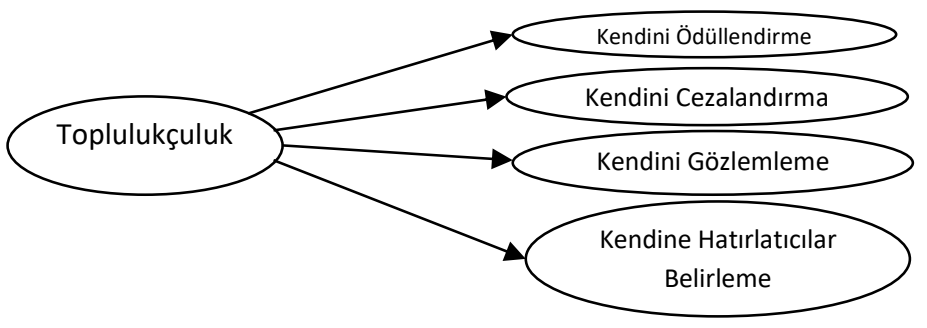

Şekil 1. Araştırma Modeli

Araştırmanın temel hipotezleri aşağıdaki gibi belirlenmiştir:

- H1: Toplulukçuluk kültürel boyutunun davranış odaklı öz liderlik stratejilerinden kendini ödüllendirme stratejisi üzerinde anlamlı bir etkisi vardır.

- H2: Toplulukçuluk kültürel boyutunun davranış odaklı öz liderlik stratejilerinden kendini cezalandırma stratejisi üzerinde anlamlı bir etkisi vardır.

- H3: Toplulukçuluk kültürel boyutunun davranış odaklı öz liderlik stratejilerinden kendini gözlemleme stratejisi üzerinde anlamlı bir etkisi vardır.

- H4: Toplulukçuluk kültürel boyutunun davranış odaklı öz liderlik stratejilerinden kendine hatırlatıcilar belirleme stratejisi üzerinde anlamlı bir etkisi vardır.

\section{Araştırmanın Örneklemi}

Ankara'daki hizmet sektöründe çalışan 374 birey araştırmanın örneklemini oluşturmaktadır. Örneklem seçiminde kolayda örneklem yöntemi kullanılmıştır. Araştırma kapsamındaki katılımcıların \%56,3' ü kadın; \%43,7' si erkektir. Katılımcıların yaklaşık \% 84,3' ü, 21-40 yaş aralığındadır.

\section{Araştırmada Kullanılan Ölçekler}

Araştırma kapsamında Hofstede (1980)'nin tanımladığı boyutlar bağlamında, Chelariu vd. (2008) tarafından hazırlanan ve Şeşen (2010) tarafından Türkçe'ye uyarlanan Toplumsal Kültürel Değerler Ölçeği'nin 
toplulukçuluk boyutuna ait altı maddesi kullanılmıştır. Araştırmada kullanılan bir diğer ölçek ise öz liderlik ölçeğidir. Houghton ve Neck (2002) tarafından geliştirilen Revize Edilmiş Öz Liderlik Ölçeği'nin Tabak vd. (2009) tarafından Türkçeye uyarlaması yapılmış olan Öz Liderlik Türkçe Formu'nun davranış odaklı stratejileri belirleyen maddeleri kullanılmıştır. Davranış odaklı öz liderlik stratejileri, kendini ödüllendirme ( 3 madde), kendiniz cezalandırma (4 madde), kendini gözlemleme ( 4 madde) ve kendine hatırlatıcılar belirleme ( 2 madde) alt boyutlarından oluşmaktadır.

\section{Bulgular}

\section{Ölçeklerin Geçerliliği}

Araştırmanın yapısal geçerliliğini sağlamak amacıyla doğrulayıcı faktör analizi yapılmıştır. Çalışmanın araştırma modeline bütün bir yapıda doğrulayıcı faktör analizi (overall confimatory factor analysis) uygulanmıştır. AMOS 22 programı kullanılarak yapılan analizde Maximum likelihood tahmin yöntemi kullanılmıştır.

Literatürde; uyum istatistiklerinin değerlendirilmesinde en çok kullanılan uyum indeksleri; $\chi 2 / d f$, GFI, CFI ve RMSEA 'dır. Bu endekslere ait eşik değerler ve modele ait uyum iyiliği değerleri Tablo 1' de verilmiştir. Buna göre, çalışmada kullanılan ölçeklerin geçerliliği bütün bir yapıda doğrulayıcı faktör analizi yapılarak sağlanmıştır. Analizde modifikasyon kullanılmamıştır.

Tablo 1: Uyum İyiliğine İlişkin İstatistiksel Değerler ile Araştırma Modeline Ait Değerler(Meydan ve Şeşen 2011, s.37; Yaşlıŏ̆lu, 2017, s.77)

\begin{tabular}{lllll}
\hline $\begin{array}{l}\text { Uyum } \\
\text { Indeksleri }\end{array}$ & CMIN/DF & GFI & CFI & RMSEA \\
\hline Eşik Değerler & $\leq 4-5$ & $\geq 0,85$ & $\geq 0,90^{*}$ & $\leq 0,08$ \\
\hline $\begin{array}{l}\text { Modele } \\
\text { Ait Değerler }\end{array}$ & 2,945 & 0,897 & 0,927 & 0,070 \\
\hline$\quad p<0.01$ & & & &
\end{tabular}

Yüksek birleşme geçerliğinin sağlanabilmesi için yüksek faktör yüklerinin olması gerekmektedir. Böyle bir durum, gizil yapının ortak bir noktada 
birleştiğini göstermektedir. Faktör yüklerinin 0,5 veya daha yüksek olması; idealinde ise 0,7 veya yüksek olması beklenmektedir.

Tablo 2: Tüm Değişkenleri Kapsayan Doğrulayıcı Faktör Analizi Sonuçları

\begin{tabular}{lll}
\hline Madde & Faktör Yükleri & Cronbach Alpha $(\boldsymbol{\alpha})$ \\
\hline Toplulukçuluk & &, 863 \\
\hline TOPL1 &, 620 & \\
TOPL2 &, 758 & \\
TOPL3 &, 874 & \\
TOPL4 &, 850 & \\
TOPL5 &, 511 & \\
TOPL6 &, 698 &, 814 \\
\hline Kendini Cezalandırma &, 488 & \\
\hline KCEZA1 &, 939 & \\
KCEZA2 &, 679 & \\
KCEZA3 &, 803 & \\
KCEZA4 & & \\
\hline Kendini Gözlemleme &, 718 \\
\hline KGÖZLE1 &, 611 & \\
KGÖZLE2 &, 780 &, 849 \\
KGÖZLE3 &, 827 & \\
KGÖZLE4 & & \\
\hline Kendini Ödüllendirme &, 753 &, 737 \\
\hline KÖDÜL1 &, 818 \\
KÖDÜL2 &, 864 & \\
KÖDÜL3 & & \\
\hline Kendine Hatırlatıclar Belirleme &, 843 \\
\hline HATIRLATICI1 &, 695 \\
HATIRLATICI2
\end{tabular}

Not: TOPL: Toplulukçuluk, KCEZA: Kendini Cezalandırma, KGÖZLE: Kendini Gözlemleme, KÖDÜL: Kendini Ödüllendirme, HATIRLATICI: Kendine Hatırlatıcı Belirleme

Tablo 2 incelendiğinde bütün değerlerin kendini cezalandırma boyutunun ilk maddesi dışında gerekli kabul edilen değer olan $0,5^{\prime}$ in üstünde olduğu görülmektedir. İlgili madde 0,5 değerine çok yakın olduğundan ve analizden çıarıldığında uyum iyiliği değerlerini düşürdügünden analiz dışı bırakılmamıştır. Bu nedenle faktör yükleri anlamında geçerlikle ilgili bir sorunun olmadığı ifade edilebilir. Birleşme geçerliğinin bir diğer göstergesi de güvenirliktir. Bu anlamda yapılan 
tartışmalarda hangi güvenirlik yönteminin daha iyi olduğu test edilmektedir. Farklı güvenirlik yöntemleri ile bu durum değerlendirilmektedir (Hair ve diğerleri, 2010, s. 678). Tablo 2' de güvenirlikle ilgili ilk olarak Cronbach Alfa değerlerinin hesaplanmış olduğu görülmektedir. Bu değerlerin bütün boyutlar için alan yazında kabul edilen değer olan $0,70^{\prime}$ in üstünde olduğu görülmektedir.

Tablo 3: Değişkenler Arasındaki İlişkiler

\begin{tabular}{llllll}
\hline Değişkenler & $\mathbf{( 1 )}$ & $\mathbf{( 2 )}$ & $\mathbf{( 3 )}$ & $\mathbf{( 4 )}$ & $\mathbf{( 5 )}$ \\
\hline Toplulukçuluk (1) & 1 & & & & \\
K. Ödül (2) &, $374^{* *}$ & 1 & & & \\
K. Ceza (3) &,$- 315^{* *}$ &,$- 285^{* *}$ & 1 & & \\
K. Gözlem (4) &, $492^{* *}$ &, $651^{* *}$ &,$- 345^{* *}$ & 1 & \\
K. Hatırlatıcı (5) &, $425^{* *}$ &, $559^{* *}$ &,$- 316^{* *}$ &, $775^{* *}$ & 1 \\
\hline
\end{tabular}

Araştırmada değişkenler arasında korelasyon olup olmadığı analiz edilmiş ve elde edilen sonuçlar Tablo 3 'te verilmiştir. Buna göre toplulukçuluk ile kendi kendini ödüllendirme ( $\mathrm{r}=374)$, kendini gözlemleme $(\mathrm{r}=492)$ ve kendine hatırlatıcılar belirleme $(\mathrm{r}=425)$ arasında pozitif; kendini cezalandırma arasında ise ( $\mathrm{r}=-315)$ negatif bir ilişki bulunmuştur. Kendini ödüllendirme ile kendini cezalandırma ( $\mathrm{r}=-285)$ arasında negatif yönlü, kendini gözlemleme $(\mathrm{r}=651)$ ve kendine hatırlatıcılar belirleme $(\mathrm{r}=559)$ arasında pozitif yönlü bir ilişkiye rastlanmıştır. Kendini cezalandırma ile kendini gözlemleme ( $\mathrm{r}=-345)$ ve kendine hatırlatıcılar belirleme ( $\mathrm{r}=-316)$ arasında negatif yönlü; kendini gözlemleme ve kendine hatırlatıcılar belirleme arasında (r=775) ise pozitif yönlü ilişki tespit edilmiştir.

\section{Araştırma Hipotezlerin Test Edilmesi}

Araştırma hipotezlerini test etmek için yapısal eşitlik modellemesi kullanılmıştır. Meydan ve Şeşen (2011, s.97) yol analizini araştırmacının kuramsal olarak kurguladığı modelde değişkenler arasındaki ilişkilerin gücünü ve anlamlı olup olmadığını test etmek şeklinde tanımlamıştır. Test sırasında birden çok değişkenin karşılıklı etkileşimleri analiz edilmekte ve bütüncül bir bakış açısı ile değişkenler arasındaki ilişkiler ortaya konmaktadır. Bu çalışmada yapısal eşitlik modellemesine ilişkin 
sonuçlar $\chi 2 / d f=3,55 ;$ GFI=0,890; CFI $=0,909 ;$ RMSEA=0,080; $p<0.01$ şeklinde bulunmuştur.

Tablo 4'te bulunan yol analizi sonuçları incelendiğinde, hipotezlerin tümünün desteklendiği görülmüştür.

Tablo 4: Araştırma Modeli İçin Yol Analizi Hipotezlerinin Sonuçları

\begin{tabular}{llllll}
\hline $\begin{array}{l}\text { Hipo- } \\
\text { tez }\end{array}$ & $\begin{array}{l}\text { Yapısal } \\
\text { İlişki }\end{array}$ & $\begin{array}{l}\text { Std. } \\
\text { Re- } \\
\text { gresyon } \\
\text { Kaysayıs1 } \\
(\boldsymbol{\beta})\end{array}$ & $\begin{array}{l}\text { Std. } \\
\text { Hata }\end{array}$ & $\begin{array}{l}\text { Anlam- } \\
\text { l1lık }\end{array}$ & Hipotez \\
\hline H1 & KÖDÜL<--- TOPL. &, 499 &, 063 & $\mathrm{p}<0.0001$ & Desteklendi \\
H2 & KCEZA<--- TOPL. &,- 358 &, 048 & $\mathrm{p}<0.0001$ & Desteklendi \\
H3 & KGÖZLEM<--- TOPL. &, 692 &, 060 & $\mathrm{p}<0.0001$ & Desteklendi \\
H4 & HATIRLATICI<--- TOPL. &, 639 &, 064 & $\mathrm{p}<0.0001$ & Desteklendi \\
\hline $\boldsymbol{p}<\mathbf{0 . 0 1}$ & & & & &
\end{tabular}

Analiz sonuçlarına göre, katılımcıların davranış odaklı öz liderlik stratejilerini toplulukçuluk algılarının etkilediği görülmüştür. Buna göre toplulukçuluk algısından en çok etkilenen değişkenler sırasıyla kendini gözlemleme (p:0,0001; $\beta: 0,692)$, kendine hatırlatıc1lar belirleme ( $p: 0,0001$; $\beta: 0,639)$ ve kendini ödüllendirme (p:0,0001; $\beta: 0,499)$ olduğu görülmüştür. Toplulukçuluk algısının kendini cezalandırma stratejisi üzerinde ise negatif yönlü ve anlamlı bir etkisi bulunmaktadır (p:0,0001; $\beta$ : -0,358).

\section{Sonuç ve Öneriler}

$\mathrm{Bu}$ çalışmanın amacı, toplulukçu kültürel değer boyutunun, bireylerin davranış odaklı öz liderlik stratejilerini kullanmaları üzerinde etkisi olup olmadığını incelemektir. Araştırma sonucunda toplulukçuluk boyutunun tüm davranış odaklı öz liderlik stratejileri üzerinde anlamlı etkileri olduğu görülmüştür. Toplulukçuluk algısının öz liderlik stratejilerinden sadece, kendini cezalandırma stratejisi üzerinde negatif yönlü ve anlamlı bir etkisinin bulunmuştur. Toplulukçu kültürlerin olduğu örgütlerde kişiler arası ilişkilerin ön plana çıkması nedeniyle, bireyler hata yaptıklarında örgüt tarafından cezalandırılma davranışı genellikle tercih edilmeyebilir. Bu nedenle de toplulukçu kültürlerdeki örgütlerde bireyler 
kendilerini cezalandırma eğiliminde olmayabilirler. Bununla birlikte çalışanların toplulukçu kültüre ait örgütlerde çalışıyor olmalarının ve toplulukçu bir kültürün bireyleri olmalarının, öz liderlik stratejilerini uygulamalarına engel olarak gözükmediği söylenebilir.

Yerli alan yazında öz liderlik ile ilgili yapılan çalışmalara da bakıldığında kendini cezalandırma boyutu görece daha düşük bir ortalamaya sahip olsa da, tüm davranış odaklı öz liderlik stratejilerinin ortalamalarının, bu çalışmada da olduğu gibi orta değerin üzerinde olduğu görülmüştür (Arlı ve Avc1, 2017, s.460; Tabak vd., 2013; Ay, 2017, s.935).

Kültürel değerler açısından incelendiğinde, baskın ve bağımsız bir içsel bağdaşıma sahip oldukları bilinen bireyciler, örneğin, ilerleme ve başarı gibi olumlu sonuçlara yönelik biliş ve davranışlarının düzenlenmesini destekleyen öz-liderlik stratejilerini kullanabilirler. Bu, bireycilerin, toplulukçulardan daha zorlu hedefler koyma, hedeflere ulaşma çabasını arttırmak kişisel ödüller uygulama ve yapıcı davranışları biçimlendirmek için kullanılan kendine hatırlatıcılar belirleme (örneğin, notlar, motivasyonel posterler) stratejilerini kullanmalarının daha muhtemel olduğunu göstermektedir. Buna karşılık, toplulukçular başkalarıyla uyum içinde olmaya ve diğerlerinin önemli beklentilerini yerine getirmeye çalışırlar. Toplulukçular, olumsuz sonuçlardan kaçınmaya daha fazla önem verdiklerinden, sosyal uyumu sürdürme amaçlarını tehlikeye atabilecek başarısızlık ve hatalardan kaçınmak arzularıyla önleyici odaklı davranışları daha yüksek olasılıkla sergilerler. Bu nedenle toplulukçuların bilişlerini ve davranışlarını olumsuz sonuçlardan uzak tutmak için öz-liderlik stratejileri kullanmaları beklenir (Ho ve Nesbit, 2013, s.242). Buradan hareketle öz liderlik stratejilerinin, hem bireyci hem toplulukçu kültürlerde uygulandığı ve bu araştırmada da görüldüğü gibi toplulukçuluk düzeyi arttıkça öz liderlik stratejilerinin de artmaya devam edeceği söylenebilir.

Yukarıda belirtilen varsayımın, yapılan bu çalışma ile toplulukçu bir kültürü yansitan Türkiye örnekleminde doğrulandığı söylenebilir. Sakal ve Aytekin (2014)'in çalışmalarında bireycilik-toplulukçuluk paradigmasını açıklarken kullandıkları "Ben varım çünkü biz varız" Malawi deyişi de toplulukçu kültürlerde bireylerin desteklendiği ve öz liderlik davranışları sergilenmesinin toplumun yararını amaçladığı; bireylerin, ben kendimi yönetebilirsem ve başarılı olabilirsem bunu toplum yararına 
kullanıp, toplum için bir şeyler yapabilirim düşüncesinin de desteklediği söylenebilir.

Araştırma sınırlılıkları arasında verilerin sadece toplulukçu bir kültüre sahip olan Türkiye' den toplanmış olması sayılabilir. Günümüz şartlarında iş yaşantısında, öz liderlik stratejilerini uygulamanın çalışan performansını arttıracağı varsayımı yöneticilerin bu stratejileri anlayıp, geliştirmeleri ve uygulamaları için kritik öneme sahiptir. Bu nedenle Neubert ve Wu (2006)'nun da çalışmasında amaçladı̆̆ı gibi yapılan kültürlerarası çalışmalar, öz liderlik kavramının gelişmesine ve genellenebilmesine katkı sağlamaktadır. Bu sayede farklı kültürlerden çalışanların bulunduğu işletmelerde genellenebilir bir öz liderlik stratejisi çalışması mümkün olabilir. Çalışmanın bir diğer sınırlılı̆̆ ise araştırmaya toplumsal kültürel boyutların tümünün dahil edilmemesidir.

$\mathrm{Bu}$ çalışmada toplumsal kültür boyutlarından toplulukçuluk boyutu araştırmaya dahil edilmiştir. Gelecek çalışmalarda diğer kültürel boyutların öz liderlik stratejileri üzerindeki etkilerinin araştırılması bir öneri olarak sunulabilir. Ayrıca bireyci özellikler taşıyan bir kültürden de veriler toplanarak, toplulukçu kültür özelliklerine sahip Türkiye'de karşılaştırmalı bir çalışma alan yazında böyle bir araştırmaya rastlanmadığından, yapılabilir.

Öz liderlik stratejisi, her ne kadar paylaşımcı liderlik içerisinde liderle birlikte izleyicilerin de öz liderlik becerilerine sahip olması gerektiğini savunsa da, araştırmanın, Türkiye örnekleminde sadece yönetici pozisyonunda çalışanlarla yapılıp, bireysel performansı arttırmak için kullanılabilen öz liderlik stratejilerini, yöneticilerin bireycilik algılarının mı yoksa toplulukçuluk algılarının mı etkilediğinin araştırılması son bir öneri olarak sunulabilir. 


\title{
EXTENDED ABSTRACT
}

\section{The Impact of Collectivistic Culture on Self Leadership: A Study in Service Sector}

\author{
Ayşen Akbaş Tuna
}

Ankara Hacı Bayram Veli University

Over the past two decades, multi-national organizations have restructured, and moved toward decentralized, organic-type organizational structures in response to the rapid changes in the business environment. People with high levels of capacity and skills in self-direction and selfinfluence should respond more successfully and effectively to the dynamic changes of organization structures and environments. Thus, selfleadership which is defined as "a self-influence process through which people achieve the self-direction and self-motivation necessary to perform", has become an important concept in management research (Ho and Nespit, 2013, p.241). Business executives have also embraced self-leadership concepts through training programs designed to increase self-leadership skills and behaviors in the workplace (Neck and Houghton, 2006, p.271).

Due to the increasing number of multinational organizations in the world, it has been possible for employees with different cultural values to work together. It is important that self-leadership skills are improved in employees who can adapt to the organizational structures of multinational enterprises. How this will affect the business environment has come up as an issue that needs to be investigated. Therefore, studies have been conducted on the intercultural applicability of the concept of self leadership. According to Georgianna (2007, p.573), the question emerges: whether there is a difference in performance between individuals in cultures that emphasize strong independence from others (i.e. individualist or Western cultures) and individuals in cultures that emphasize the importance of group membership (i.e. collectivist or non Western cultures) due to the self-leadership strategies found in the respective cultures. 
Georgianna (2007) argues that the studies on self-leadership in Europe, North America and Australia do not have universal validity, and that research findings can only be generalized in these regions. For this reason, studies have no use for cultures other than those called Western culture. Other cultures other than Western culture are changing rapidly in the process of globalization. Since Western cultures mainly affect non-Western cultures through trade, migration and dissemination of information technologies, these cultures undergo significant changes in the process of globalization. Expanding into these cultures, Western companies face significant cultural challenges in terms of communication styles, use of information power, learning and goal setting, and the management of nonWestern employees by Western managers poses different challenges. Therefore, the conditions for the implementation of studies on culture and self-leadership in non-western cultures have matured.

In this study, it was investigated whether collectivism dimension, which is one of the social culture dimensions, has an effect on behaviororiented self-leadership strategies. In the search of local literature, there was no study on the relationship between social cultural values and self leadership. Therefore, it is thought that the research will contribute to the literature.

One of the variables used in this study is self leadership. Self-leadership is a process through which individuals control their own behavior, influencing and leading themselves through the use of specific sets of behavioral and cognitive strategies (Neck and Houghton, 2006, p.270). Here, self-leadership is conceptualized as a comprehensive self-influence perspective that concerns leading oneself toward perfor- mance of naturally motivating tasks as well as managing oneself to do work that must be done but is not naturally motivating (Manz, 1986, p.589).

Self-leadership strategies are usually grouped into the three primary categories of behavior-focused strategies, natural reward strategies and constructive thought pattern strategies (Houghton at al., 2002; Neck and Houghton, 2006; Ho and Nesbit, 2013). Behavior-focused strategies used in the study, strive to heighten an individual's self-awareness in order to facilitate behavioral management, especially the management of behaviors related to necessary but unpleasant tasks. Behavior-focused strategies 
include self-observation, self-goal setting, self-reward, self-punishment and self-cueing (Neck and Houghton, 2006, p.271).

Another variable used in the study is collectivism that is one of the social culture variables. Individualism stands for a preference for a loosely knit social framework in society wherein individuals are supposed to take care of themselves and their immediate families only. Its opposite, Collectivism, stands for a preference for a tightly knit social framework in which individuals can expect their relatives, clan, or other in-group to look after them in exchange for unquestioning loyalty (it will be clear that the word "collectivism" is not used here to describe any particular political system). The fundamental issue addressed by this dimension is the degree of interdependence a society maintains among individuals (Hofstede, 1984, p.83).

Hofstede (1980) described individualism and not individualism and collectivism; that is, he made the assumption that the opposite of individualism is collectivism, and that once high and low individualism were perationalized, there would be no need to separately operationalize collectivism. This simplifying assumption was accepted by many researchers, but a recent meta- analysis showed that individualism and collectivism are orthogonal. This means that individualism and collectivism, and their effects on psychological processes, must each be tested separately - presumably because both exist to some extent in all societies and influence psychological processes when they are made salient or brought to mind via situational priming (Oyserman, 2006).

Albeit self-leadership assumes individuals to have degrees of autonomy in setting their own goals, this cultural dimension questions the extent that self-leadership is likely to happen in cultures that are more collectivistic than the USA. Considering self-leadership as a self-influencing process and a set of strategies aiming at the enhancement of one's performance, we have to believe that this theory may be applied to most societies (Alves, at.al., 2006). As a result of this research, it has been seen that all dimension of collectivism has significant effects on all behavior oriented self leadership strategies. it was concluded that collectivism has significant and positive effects on behavior-oriented self-leadership strategies named self-rewarding, self-observation and self-reminder. Also collectivism has a significant negative impact on the strategy of self-punishment. Because of the interpersonal relations in organizations with collectivist 
cultures, the behavior of punishment by the organization when individuals make mistakes may not be preferred. For this reason, individuals in organizations in collectivist cultures may not tend to punish themselves. However, it can be said that the fact that the employees are working in organizations belonging to the collectivist culture and are being members of a collectivist culture do not seem to be an hindrance to the implementation of self-leadership strategies.

Individualists (who are known to hold a predominant independent self-construal) may, for example, use self-leadership strategies that support the regulation of their cognitions and behaviors toward positive outcomes such as advancement and achievement. We expect that such individualists are more likely than collectivists to initiate the setting of challenging goals, apply self-rewards imposed for energizing the effort towards goal achievement, and construct certain concrete environmental cues (e.g. notes, motivational posters) used for shaping constructive behaviors. The application of these three self-leadership strategies may enhance the individualists' perceived control and selfefficacy in attaining their desired outcomes. In contrast, collectivists (who are known to hold a predominant interdependent self-construal) strive to harmoniously fit in with others and to live up the expectations of significant others. Since collectivists place more emphasis on avoiding negative outcomes, they are more likely to exhibit prevention focus behaviors in their desire to avoid failure and mistakes that may jeopardize their goals of maintaining social harmony. Thus collectivists are expected to use self-leadership strategies in order to regulate their cognitions and behaviors away from negative outcomes (Ho and Nesbit, 2013, p.242). From this point of view, it can be said that self-leadership strategies are applied in both individualist and collectivist cultures and as seen in this research, self-leadership strategies will continue to increase as the level of collectivism increases.

As a suggestion: Although the self-leadership strategy claims that selfleadership skills should be shared with the leader in shared leadership, another research may be done only by working in executive positions in Turkey sample. It can be researched whether the self-leadership strategies that can be used to increase individual performance are influenced by the perceptions of individualism or perceptions of collectivism of the managers. 


\section{Kaynakça / References}

Alves, J. C., Lovelace, K. J., Manz , C. C., Matsupura, F., Toyasaki, D. ve Ke, K. (2006). A cross-cultural perspective of self-leadership. Journal of Managerial Psychology, 21 (4), 338-359.

Arli, Ö. ve Avci, A. (2017). Öz kendilik değerlendirmesinin öz liderlık davranışları üzerinde etkisi: İlköğretim öğretmenleri üzerine bir araştırma. Mehmet Akif Ersoy Üniversitesi, Sosyal Bilimler Enstitüsü Dergisi, 9 (22),455-468.

Ay, G. (2017). Yönetici ve yönetici asistanlarının öz liderlik düzeylerinin belirlenmesine yönelik bir araştırma. Uluslararası Sosyal Araştırmalar Dergisi, 10 (52), 929-940.

Doğan, S. ve Şahin, F. (2008). Kendi kendine liderlik ölçeğinin türkçe uyarlaması, geçerlilik ve güvenilirlik çalışması. H.Ü.İktisadi ve İdari Bilimler Fakültesi Dergisi, 26(1), 139-164.

Dörtyol, İ.T. (2012). Ulusal kültürün algllanan hizmet kalitesi ve algllanan müşteri değeri üzerindeki etkisi: Turizm sektöründe bir araştırma. Yayımlanmamış Doktora Tezi, Cumhuriyet Üniversitesi Sosyal Bilimler Enstitüsü, Sivas.

Georgianna S. (2007). Self-leadership: A cross-cultural perspective. Journal of Managerial Psychology, 22 (6), 569-589.

Hair, J.F., Black, W.C., Babin, B.J. ve Anderson, R.E. (2010). Multivariate data analysis ( $7^{\text {th }}$ Ed.), Prentice Hall.

Hofstede, G. (1983), The cultural relativity of organizational practices and theories, Journal of International Business Studies, 14, 75-89.

Hofstede, G. (1984), Cultural differences in management and planning, Asia Pacific Journal of Management, 1, 81-99.

Hofstede, G. (2011). Dimensionalizing cultures: The hofstede model in context. Online Readings in Psychology and Culture, 2(1), 3-26.

Ho, J. ve Nesbit, P.L. (2013). Exploring self-leadership across Eastern and Western cultures. Journal of Service Science and Management, 6, 241249.

Houghton J. D. ve Neck C.P. (2002). The revised self-leadership questionnaire: Testing a hierarchical factor structure for self-leadership, Journal of Managerial Psychology, 17 (8), 672-691. 
Houghton, J. D., Dawley, D. ve Diliello, T. C. (2012). The abbreviated selfleadership questionnaire (ASLQ): A more concise measure of selfleadership. International Journal of Leadership Studies, 7(2), 216 232.

Houghton, J.D., Carnes, A. ve Ellison, C.N. (2014). A cross-cultural examination of self-leadership: Testing for measurement invariance across four cultures. Journal of Leadership EOrganizational Studies, $21(4), 414-430$.

Manz, C. (1986). Self-leadership: Toward an expanded theory of self-influence processes in organizations. The Academy of Management Review, 11(3), 585-600.

Manz, C.C. ve Jr Sims, H.P. (1991), SuperLeadership:Beyond the myth ofheroic leadership. Organizational Dynamics, Spring, 19(4), 18-35.

Neck, C.P., ve Houghton, J.D. (2006). Two decades of self-leadership theory and research:Past developments, present trends, and future possibilities, Journal of Managerial Psychology, 21 (4), 270-295.

Neubert, J.M. ve Wu, J.C. (2006) An investigation of the generalizability of the Houghton and Neck Revised Self-Leadership Questionnaire to a Chinese context, Journal of Managerial Psychology, 21 (4), 360-373.

Oyserman, D. (2006). High power, low power, and equality: Culture beyond individualism and collectivism, Journal of Consumer Psychology, 16 (4), 352-356.

Sakal, Ö.ve Aytekin, İ. (2014). Bireycilik-Toplulukçuluk Değerlerinin Başarı Amaç Yönelimlerine Etkisi Üzerine Karşılaştırmalı Bir Araştırma, Kafkas Üniversitesi İktisadi ve İdari Bilimler Fakültesi Dergisi, 5 (8), 45-66.

Şeşen, H. (2010). Öncülleri ve sonuçlarn ile iç girişimcilik: savunma sanayinde bir araştırma, Yayımlanmamış Doktora Tezi, KHO Savunma Bilimleri Enstitüsü, Ankara.

Tabak. A., Siğri, Ü. ve Türköz, T. (2013). Öz liderlik ölçeğinin türkçeye uyarlanması çalışması. Türk Dünyası Sosyal Bilimler Dergisi,67, 213246.

Ton, İ.A. (2008). Bireycilik-toplulukçuluk ve güvenin işyerinde güçlendirmeye olan etkileri, Yayınlanmış Doktora Tezi, Marmara Üniversitesi, Beta Yayıncılık, İstanbul. 
Yaşlığlu, M.M. (2017). Sosyal bilimlerde faktör analizi ve geçerlilik: Keşfedici ve doğrulayıcı faktör analizlerinin kullanılması, İstanbul Üniversitesi İşletme Fakültesi Dergisi, 46(Special Issue/Özel Sayı), 74-85.

http://www.tdk.gov.tr

\section{Kaynakça Bilgisi / Citation Information}

Tuna-Akbaş, A. (2019). Toplulukçu kültürün öz liderlik algısı üzerine etkisi: Hizmet sektöründe bir araştırma.OPUS-Uluslararası Toplum Araştırmaları Dergisi, 12(18. UİK Özel Sayısı), 410-438. DOI: 10.26466/opus. 585045 